\title{
TRADE-OFF DO GESTOR PÚBLICO: CUSTO DE OBTENÇÃO PELO PROGRAMA DE AQUISIÇÃO DE ALIMENTOS, QUE FOMENTA A AGRICULTURA FAMILIAR E PREGÃo ELETRÔNICO
}

\author{
Cláudia Monalisa de Souza Silva \\ Pontifícia Universidade Católica do Rio de Janeiro \\ Rua Marquês de São Vicente, 225, Gávea - Rio de Janeiro, RJ - Brasil - 22451-900 \\ monalisadaflavinha@gmail.com \\ Lincoln Wolf de Almeida Neves \\ Pontifícia Universidade Católica do Rio de Janeiro \\ Rua Marquês de São Vicente, 225, Gávea - Rio de Janeiro, RJ - Brasil - 22451-900 \\ lincoln@puc-rio.br \\ Bruno da Silva Teixeira \\ Marinha do Brasil \\ Avenida Brasil, 10.500, Olaria - Rio de Janeiro, RJ - Brasil - 21012-350 \\ ctbruno.teixeira@gmail.com \\ Erica Von Raschendorfer Bastos Maia \\ Marinha do Brasil \\ Avenida Brasil, 10.500, Olaria - Rio de Janeiro, RJ - Brasil - 21012-350 \\ erica_von24@yahoo.com.br
}

\begin{abstract}
RESUMO
O Governo Federal promoveu o Programa de Aquisição de Alimentos (PAA) desde 2003 como parte do programa fome Zero, almejando com ele fomentar o acesso da Agricultura Familiar no mercado das compras públicas e, adicionalmente, o incremento no desenvolvimento econômico e social, estabelecendo por meio do Decreto 8.473/15 a obrigatoriedade de execução de parte do orçamento anual dos órgãos da Administração Pública Federal, para aquisição neste programa. Tal fato enseja o estudo comparativo do custo de aquisição pelo PAA, na modalidade Compra Institucional (CI) e o Pregão Eletrônico, no Sistema de Registro de Preços (PE-SRP) com objetivo de identificar qual formato que promove a maior vantagem econômica para a Administração. Para tanto, foi realizada uma pesquisa exploratória descritiva com abordagem quantitativa, propondo uma análise sobre as aquisições de alimentos no Centro de Obtenção da Marinha no Rio de Janeiro e no Governo Federal. Como resultado, obteve-se que os valores medianos das aquisições pelo PAA-CI são em sua maioria mais caros que os praticados no PE-SRP. Contudo, a análise do PAA-CI ainda é incipiente e espera-se que, com maiores incentivos ao programa ocorra uma aceleração do crescimento da oferta e, por consequência, queda dos preços.
\end{abstract}

Palavra-Chave: Agricultura Familiar, Programa de Aquisição de Alimentos, Compra Institucional e Compras Públicas. 


\section{ABSTRACT}

The Federal Government has promoted the Food Acquisition Program (PAA) since 2003 as part of the Zero Hunger program, aiming to foster the access of Family Farming in the public procurement market and, in addition, the increase in economic and social development, establishing by Decree 8.473 / 15 requires the execution of part of the annual budget of the Federal Public Administration bodies, for acquisition in this program. This fact leads to the comparative study of the acquisition cost by the PAA, in the Institutional Purchase mode (CI) and the Electronic Auction, in the Price Registration System (PE-SRP) in order to identify which format promotes the greatest economic advantage for the Administration. To this end, a descriptive exploratory research with quantitative approach was performed, proposing an analysis on food purchases at the Navy Obtaining Center in Rio de Janeiro and the Federal Government. As a result, it was found that the median values of PAACI acquisitions are mostly more expensive than those practiced by PE-SRP. However, the analysis of the PAA-CI is still incipient and it is expected that, with greater incentives for the program, there will be an acceleration of supply growth and, consequently, falling prices.

Keyword: Family Farming, Food Acquisition Program, Institutional Purchasing and Public Purchasing.

\section{Como Citar:}

SILVA, Cláudia Monalisa de Souza; NEVES, Lincoln Wolf de Almeida; TEIXEIRA, Bruno da Silva; MAIA, Erica Von Raschendorfer Bastos. Trade-off do Gestor Público: custo de obtenção pelo Programa de Aquisição de Alimentos, que fomenta a agricultura familiar e pregão eletrônico. In: SIMPÓSIO DE PESQUISA OPERACIONAL E LOGÍSTICA DA MARINHA, 19., 2019, Rio de Janeiro, RJ. Anais [...]. Rio de Janeiro: Centro de Análises de Sistemas Navais, 2019.

\section{INTRODUÇÃO}

É notório o poder que a Administração Pública possui no contexto das compras governamentais, principalmente no tocante a capacidade de prover mudanças no cenário produtivo e de consumo da sociedade [1]. Nesse sentido, o papel do gestor público é fundamental, pois ele é o responsável pela coordenação e execução do modus operandi dos processos de aquisição, visando à seleção da proposta mais vantajosa [2].

Desde 2013, o Pregão Eletrônico (PE), no Sistema de Registro de Preço (SRP), foi a maneira fomentada para realizar aquisições de gêneros alimentícios, dada a classificação de bem comum [3; 4]. Entretanto, com o advento do Decreto 8.473 de 22 de junho de 2015, houve um incremento nas citadas aquisições e, a partir de 2016, a Administração Pública Federal passou a ser obrigada a dedicar um percentual mínimo de 30\% dos seus recursos financeiros à aquisição de alimentos produzidos por agricultores familiares e suas organizações [5]. Assim, salvo o contido no artigo $2^{\circ}$ do Decreto 8.473/15, os Estados, Municípios e Órgãos Federais da Administração Direta e Indireta foram compelidos a comprar alimentos da Agricultura Familiar (AF) por meio de Chamadas Públicas (CP) com dispensa de licitação, dentro do percentual supramencionado.

Ao explorar esse novo modelo de aquisição obteve-se uma inovação no rito procedimental que rompeu paradigmas tradicionais. Frente a esses dois formatos distintos de aquisição o gestor público é posto diante de um paradoxo acerca da vantagem da compra, 
considerando que a aquisição por licitação e pelo Programa de Aquisição de Alimentos (PAA) possuem objetivos díspares [2; 6].

Desse modo, estabeleceram-se novas determinações nos procedimentos de obtenção abrangendo as instituições públicas e os agricultores familiares. Nesse diapasão, as organizações são desafiadas a inserir o produtor rural ou as cooperativas, como potencial fornecedor à estrutura das compras públicas [7].

Assim, apesar do Programa de Aquisição de Alimentos na modalidade Compra Institucional (PAA-CI) proporcionar ao agricultor familiar uma oportunidade de comercialização dos seus produtos, não existe clareza sobre a vantagem em relação aos preços praticados nesse novo formato, quando comparado com o PE-SRP.

Por conseguinte, ao considerar a complexidade que envolve o processo de tomada de decisão da aquisição dos produtos oriundos da $\mathrm{AF}$, vinculando essa escolha à comparação com o PE, tem-se a problemática desta pesquisa pautada no conflito de interesses quanto à vantagem/economia dos preços praticados no PE-SRP e no PAA-CI.

Assim, este artigo direcionará seu foco na análise comparativa sobre a vantagem dos preços praticados nesses dois modelos distintos de compras de alimentos conduzidos no Centro de Obtenção da Marinha no Rio de Janeiro (COMRJ) no período de 2018, pelo fato desta Organização Militar (OM) ser a responsável, na Marinha do Brasil (MB), pela centralização de aquisição de gêneros alimentícios de todo território nacional, movimentando cerca de 60 milhões de reais, por ano, em aquisições de alimentos.

O presente estudo tem por objetivo geral realizar uma análise comparativa quanto à vantagem dos preços obtidos nas contratações que fomentam a AF com as praticadas nos PE e, para tanto, apresenta os seguintes objetivos específicos: i) descrever a importância da AF; ii) evidenciar o papel estratégico das compras públicas; iii) explicitar as diferenças entre os objetivos dos modelos de compra com os PE-SRP e as CP-AF; e iv) realizar uma comparação de preços entre PE-SRP e processo de CP-AF no PAA-CI.

Diante do exposto, aflora a seguinte pergunta de pesquisa: Como o fomento do governo à execução do PAA-CI tem impactado os preços das contratações públicas no âmbito da MB?

Este trabalho é relevante em função dos avanços expressivos do PAA-CI, principalmente, na esfera das Forças Armadas, salientando-se que a sua obrigatoriedade só ocorreu a partir de 2016, conforme Decreto 8.473/15. Tal importância é destacada no Relatório de Execução 2017, ao evidenciar que o Ministério da Defesa (MD), que representa a Marinha, o Exército e a Aeronáutica, comprou, em 2018, um total de R\$ 67.995.131,85 do PAA-CI e realizou $45,28 \%$ do total de CP-AF, estabelecendo-se como o principal utilizador do programa [8]. Ademais, há uma expectativa que demonstra uma oportunidade de expandir o desenvolvimento econômico social do país com essa prática.

Assim, justifica-se, com esta pesquisa, a necessidade de apresentar ao gestor público uma contribuição para tomada de decisão, sob a ótica da vantagem econômica, reforçando a comparação dos custos de aquisição no modus operandi antigo, com PE-SRP e com o PAACI, dado que a nova prática ainda é incipiente, contudo, promissora [8].

O artigo foi dividido em cinco seções, incluindo esta introdutória. A seção 2 apresenta o referencial teórico com considerações relevantes do tema em estudo. A seção 3 é dedicada à metodologia utilizada neste trabalho. A coleta e análise de dados são apresentadas na seção 4. E, por fim, as conclusões e considerações finais estão dispostas na seção 5.

\section{REFERENCIAL TEÓRICO}

A teoria abordada revelou questões que envolvem: a AF; o poder de compra do Estado; o PAA-CI; e as compras na Administração Pública. Os conceitos explorados neste 
tópico são relevantes para o entendimento dos resultados obtidos neste artigo.

\subsection{AGRICULTURA FAMILIAR (AF)}

A AF é uma vertente do desenvolvimento tanto econômico como social do Brasil, que envolve 4,4 milhões de famílias agricultoras [9]. Este segmento representa $84,4 \%$ dos estabelecimentos agropecuários brasileiros que pertencem a grupos familiares, responde por 35\% do Produto Interno Bruto (PIB) e corresponde a sete em cada dez postos de trabalho na área rural, sendo responsável por mais de $50 \%$ da produção dos alimentos pertencentes à cesta básica brasileira, contribuindo também como relevante ferramenta de gestão da inflação [10].

Somente na década de 90 o assunto ganha importância no cenário político brasileiro, passando a ser observada como elemento crítico para a economia e para o desenvolvimento local [11]. A mudança efetiva se deu por meio da consolidação de políticas públicas voltadas à AF, em que podemos destacar o Programa Nacional de Fortalecimento da Agricultura Familiar (PRONAF) e o PAA na modalidade Compra Institucional (CI), colocando o poder de compra do Estado como indutor de tais políticas.

\subsection{PODER DE COMPRA DO ESTADO}

O poder de compra do Estado tem relação direta com o papel governamental na economia e na sociedade que sofre alterações à medida em que as funções do Estado e maneiras de intervenção se modificam [12]. Nesse sentido, observa-se no texto da Convocatória de Hannover que os líderes Municipais devem se conscientizar do poder de compra do governo local e utilizá-lo no mercado para direcionar o desenvolvimento de soluções sociais e ambientalmente saudáveis [13].

Na mesma linha, tem-se que as compras públicas passaram a ser utilizadas como um dos instrumentos do Estado para a promoção do desenvolvimento social, por meio do seu poder de compra [14]. O processo licitatório é uma ferramenta utilizada pelo gestor que permite direcionar o poder de compra do Estado para gerar benefícios econômicos e socioambientais, com o incremento do emprego e da renda [15]. Utilizando-se das prerrogativas acima expostas, o governo implementou o PAA.

\subsection{PROGRAMA DE AQUISIÇÃO DE ALIMENTOS}

O PAA é um programa de governo criado pela Lei ${ }^{\circ} 10.696 / 03$, no bojo das iniciativas das políticas públicas de combate à fome e à pobreza, sob a perspectiva do direito humano à alimentação adequada e saudável, destinado a impulsionar o acesso à alimentação das populações em situação de insegurança alimentar e nutricional, por intermédio do fortalecimento da AF, com o propósito de promover o desenvolvimento econômico e social sustentável [16]. Com ele, pretende-se exercer uma ligação entre a política agrícola e de segurança alimentar estimulando a AF para atingir diversas finalidades.

As principais finalidades desta política estão relacionadas com: 1) Promover o acesso e a valorização da AF no mercado das compras públicas; 2) Promover à população o acesso à alimentação em quantidade, qualidade e regularidade necessárias, 3) Valorizar a biodiversidade e a produção orgânica e agroecológica de alimentos; 4) Fortalecer circuitos locais e regionais e redes de comercialização; 5) Estimular o cooperativismo e o associativismo; promover hábitos alimentares saudáveis em nível local e regional; e 6) Incentivar a industrialização e o processamento de alimentos [7; 17].

Por meio do PAA, o Estado compra alimentos direto de agricultores familiares sem intermediários externos à prática de execução comercial dos agricultores ou de suas organizações [18]. Projeta-se, assim, apoiar pequenos agricultores em um dos aspectos mais difíceis do processo produtivo, que é garantir o acesso ao mercado para seus produtos [19].

No PAA, os vendedores são os beneficiários e as organizações fornecedoras 
reconhecidos pela Lei 11.326/06 que possuam Declaração de Aptidão ao PRONAF- (DAP) [12].

Desde sua implementação, o PAA foi explorado apenas com o uso de quatro modalidades: 1) compra com doação simultânea; 2) Formação de Estoque; 3) Compra Direta; e 4) Incentivo à produção de leite. No transcorrer de aproximadamente dez anos de execução, duas novas modalidades foram criadas: 1) Compra Institucional (CI) e Aquisição de Sementes [6; 20; 21]. Sendo, a modalidade CI, o foco de estudo deste trabalho.

\subsubsection{Compra Institucional (CI)}

A modalidade CI do PAA foi criada a partir do Decreto $\mathrm{n}^{0} 7.775 / 12$, mediante a Resolução n 50/12 do GGPAA e, reforçada, pela Instrução Normativa $n^{\circ}$ 02/18 [20; 21; 22].

O PAA-CI é definido como estratégia de aquisição de produtos da AF na qual é factível aos hospitais públicos, restaurantes universitários, Forças Armadas, presídios, refeitórios de creches, entre outros [21; 23], promoverem compras de alimentos produzidos pela AF, por meio de CP, com recursos financeiros próprios, dispensando-se o procedimento licitatório [20; 21], desde que sejam cumpridas algumas exigências, como por exemplo, a compatibilidade dos preços com os praticados nos mercados locais [24]. Sendo assim, conforme Brasil [20; 21], a modalidade CI é a que se aplica à MB.

De acordo com Brasil [20], para que ocorra o enquadramento no PAA-CI, deve-se observar o limite por unidade familiar de $\mathrm{R} \$ 20.000,00 / a n o$ (vinte mil reais por ano) por órgão comprador, podendo alcançar até $\mathrm{R} \$$ 6.000.000,00/ano (seis milhões de reais por ano) por organização fornecedora, respeitados os limites por unidade familiar e as exigências de Declaração de Aptidão ao PRONAF, ou outros documentos definidos por resolução do GGPAA. Cabe ressaltar que os limites, mencionados nesse parágrafo, podem ser observados para mais de um órgão adquirente.

\subsubsection{Chamada Pública (CP)}

A CP é um procedimento alternativo à licitação. Ela é também utilizada para a aquisição de alimentos via PAA-CI, configurando uma dispensa de licitação, baseado na Lei $n^{0}$ 12.512/11, no Decreto $n^{0}$ 7.775/12, e na Resolução do GGPAA n ${ }^{0}$ 50/12 [17; 20; 21; 25]. O incremento da Instrução Normativa $\mathrm{n}^{0}$ 02/2018, do Ministério de Planejamento, Desenvolvimento e Gestão, tornou obrigatória realização de CP às aquisições do PAA-CI pelos órgãos da Administração Pública Federal [22].

Dessa forma, a aquisição de produtos alimentícios para o PAA-CI, pode ser realizada por dispensa de licitação, ainda que, como regra geral, a Administração Pública deva realizar procedimento licitatório para toda e qualquer aquisição de produto ou serviço [2; 17].

\subsection{COMPRAS NA ADMINISTRAÇÃO PÚBLICA}

Conforme o inciso XXI, do artigo 37, da Constituição da República Federativa do Brasil de 1988 [26], as contratações de bens e serviços da Administração Pública devem ser realizadas por meio de processo licitatório. Em 1993, a lei 8.666, regulamentou esse processo [2], e Gigante [27] salienta os formatos específicos de licitação que são utilizados para concretizar as aquisições e contratações dos órgãos públicos. Para os propósitos deste artigo, foram selecionados na discussão o PE-SRP e a dispensa de licitação.

\subsubsection{Modalidade Pregão}

O pregão é uma modalidade definida pela lei 10.520/02 [28] que traz inovações objetivando proporcionar celeridade e facilidade ao processo licitatório, por meio da desburocratização das contratações e compras públicas. 


\subsubsection{Sistema de Registro de Preços (SRP)}

Justen Filho [29] entende que o registro de preços se configura em uma relação preliminar em que o licitante e a Administração se comprometem a atender as condições pactuadas. A "formalização da Ata de Registro de Preços (ARP) gera apenas uma expectativa de direito, não existindo nenhum direito subjetivo à contratação” [30]. Em contraponto, uma aquisição proveniente de licitação, há a presunção de que a Administração tem interesse na contratação, dando ao licitante inafastável direito ao contrato [31].

O prazo de vigência da ARP é de no máximo 12 meses, incluindo eventuais prorrogações [2; 3] e torna-se um procedimento útil quando as compras são frequentes, como no caso de aquisições de gêneros alimentícios [32].

\subsubsection{Dispensa de Licitação}

A Administração Pública deve suprir suas necessidades de bens e serviços, prioritariamente, empregando procedimentos licitatórios, entretanto, existem casos específicos que caracterizam uma dispensa ou inexigibilidade de licitação, ou ainda, o caso em que as licitações são dispensadas [2]. Tais enquadramentos deverão ser tomados em conta quando a realização do certame não assegura a contratação mais vantajosa para a Administração Pública, culminando no não atingimento dos objetivos buscados pelo Estado [29]. A licitação é dispensável quando a competição se revela como um obstáculo ao atingimento do interesse público, ou seja, naqueles casos em que para melhor atender o interesse público, a lei desobriga a instauração de um procedimento licitatório [27].

\subsubsection{Influência nos preços}

O preço de equilíbrio de mercado é aquele em que a oferta se iguala à demanda, estabelecendo o preço do produto. Para o setor de compras, a oferta de preços melhora quando aumenta a concorrência [34].

Outro aspecto relevante é quanto ao custo unitário de aquisição que pode ser reduzido no momento em que ocorre a padronização e o aumento do volume das compras, promovendo um maior poder de negociação no mercado, viabilizando uma economia de escala [35], que pode ser efetivada, segundo Karjalainen [36], por meio da consolidação das demandas de unidades apoiadas em um único contrato.

\subsubsection{Proposta mais vantajosa $\mathrm{x}$ Objetivo do PAA-CI}

De acordo com o entendimento do TCU [37], o objetivo principal de obter a proposta mais vantajosa, por intermédio da ampla concorrência, não deve ser perdido nas licitações da Administração Pública. Acrescenta, ainda, que o alcance da proposta mais vantajosa se dá por meio da concorrência entre os vários licitantes, pois, dessa forma, há uma maior probabilidade de se obter um preço ou resultado mais conveniente ao interesse público [37].

Messias e Camargo [38] discorrem que o objetivo do legislador ao conceber o dispositivo que busca fortalecer a AF é o de favorecer a comunidade local e não o de estabelecer a proposta economicamente mais vantajosa à Administração, entendida como aquela que resulta no menor preço e melhor produto. Segundo as autoras, neste contexto, o fortalecimento da $\mathrm{AF}$ e da comunidade rural local torna impraticável o princípio da competitividade que é estabelecido nas licitações.

As aquisições públicas que consideram em sua análise que o menor preço é suficiente para minimizar os gastos públicos podem ser equivocadas, uma vez que não consideram as possíveis externalidades ao processo [39]. Quando o legislador possibilitou a dispensa do procedimento licitatório, considerou tais externalidades ao processo e o potencial de favorecimento do agricultor, bem como oferecer um alimento de qualidade [38].

Oldekop et al [40] afirmam que o nível de desigualdade social pode ser aprofundado 
com o aumento da concorrência, devido ao fato de que os pequenos agricultores não possuem condições de competir com os agricultores de grande escala. Quando o modelo de seleção de propostas considera o menor preço, ocorre uma concorrência entre as organizações para a venda dos gêneros alimentícios. Neste contexto, espera-se que a organização (cooperativa) que possua a melhor condição de oferta seja lograda como vencedora, sendo, normalmente, uma organização suficientemente capitalizada, configurando-se como um entrave às organizações familiares que não dispõem do mesmo aporte de capital [23].

\section{METODOLOGIA}

Esta pesquisa foi estruturada de forma exploratória e descritiva, com o objetivo de trazer uma reflexão acerca da vantagem econômica relativa à aplicação do PAA, especificamente quanto à modalidade CI, aplicadas na MB, por meio do COMRJ, em 2018.

Para isto, a pesquisa desenvolveu-se em duas fases: na primeira, realizou-se a identificação dos itens de maior criticidade referentes ao planejamento de aquisição de gêneros alimentícios e determinação de necessidades realizadas pelo Centro de Controle de Inventário da Marinha (CCIM), obtidos com uma distribuição em curva ABC [1]. Em seguida, foram utilizados dados secundários de documentos oficiais oriundos dos relatórios gerenciais extraídos do painel de preços do Governo Federal (http://paineldeprecos.planejamento.gov.br/) no ano de 2018 e resultados de CP-AF [41], pesquisa similar à de De Jesus, Nogueira, Almeida, dos Santos [42] e dados dos PE realizados pelo COMRJ e executados no mesmo período. Na segunda fase, apresentada na seção 4, os dados originários da primeira fase foram submetidos à tratamento estatístico, servindo de base para análises e interpretações posteriores.

\subsection{IDENTIFICAÇÃO DOS ITENS CRÍTICOS DE GÊNEROS ALIMENTÍCIOS}

A curva $\mathrm{ABC}$ é um método de controle de estoques que prevê a classificação dos itens com base no Princípio de Pareto, por meio do qual se conduz a identificação e a distribuição destes, pautadas na análise estatística relativas ao preço e à quantidade utilizada. O método é amplamente utilizado para identificação dos itens considerados críticos ou estratégicos para a gestão dos estoques [43].

Nesse sentido, a MB mantém uma Lista de Gêneros Alimentícios, chamada de Relação de Preços de Subsistência (RPS), utilizada, dentre outros fins, para representar a demanda dos itens solicitados anualmente. Este instrumento de planejamento permite a análise dos itens mais demandados, bem como a variação do preço e da sazonalidade, dificuldade de entrega com impacto na gestão da cadeia logística, entre outras informações, considerando a movimentação dos estoques e o atendimento de pedidos em cada período. A supracitada lista contempla 43 itens e, para fins deste estudo, a definição dos itens de maior criticidade considerou os seguintes critérios: preço, sazonalidade e demanda. Os itens de maior representatividade para a cadeia logística de gêneros alimentícios em estudo foram:

TABELA 1: gêneros de mais alta criticidade x critério prioritário para definição (continua)

\begin{tabular}{llll}
\hline \multicolumn{1}{c}{ Item } & Demanda & Sazonalidade & Preço \\
\hline Arroz Branco tipo I & & \\
$(1 \mathrm{KG})$ & & \\
Arroz Branco tipo I & & \\
$(5 \mathrm{KG})$ & & \\
Café torrado tipo II & & \\
\hline
\end{tabular}

TABELA 1: gêneros de mais alta criticidade x critério prioritário para definição (conclusão)

\begin{tabular}{cccc}
\hline Item & Demanda & Sazonalidade & Preço \\
\hline Farinha de mandioca & &
\end{tabular}


Feijão Preto Tipo I

Leite em pó instantâneo

Lombo suíno

Pernil suíno sem osso

Fonte: elaborado pelo autor.

Após a definição dos itens críticos, foi realizado o levantamento dos preços praticados nas aquisições dos gêneros alimentícios listados na Tabela 2, construindo as seguintes comparações: 1) preços praticados nos processos de CP no contexto do PAA-CI, seguida da comparação com os preços praticados no PE-SRP, ambos conduzidos pelo COMRJ no ano de 2018; 2) preços praticados nos processos de aquisição por meio do PAACI, seguida da comparação com os preços praticados nos PE-SRP, ambos conduzidos pelos Órgãos da Administração Pública no ano de 2018; e 3) preços praticados nos processos de aquisição via PE-SRP dos Órgãos da Administração, seguida da comparação com os preços praticados nas aquisições pela modalidade PAA-CI realizada pelo COMRJ, ambas análises tomando como base o ano de 2018.

Apesar de alguns produtos analisados neste artigo evidenciarem certo grau de industrialização, o que pode causar estranheza dado o que se imagina de produtos oriundos de AF, reitera-se que uma das finalidades do PAA-CI citadas no art. 19, da Lei 12.512/2011, é o incentivo à industrialização e ao processamento de alimentos [17]. Como novidade que proporciona suporte a este segmento, tem-se o estabelecimento das condições para a aquisição de produtos processados, beneficiados ou industrializados no âmbito do PAA, com a Resolução no 78/17, do GGPAA [44].

Nessa linha, Martinelli et al [45], reforçam que há uma expectativa crescente para a demanda de produtos minimamente processados e que, se a AF tiver qualificada para esse fim, pode ampliar as oportunidades no nicho mercadológico da agroindustrialização.

Por último, vale ressaltar que, para as pesquisas dos vários processos de aquisição, optou-se pela utilização da mediana como o preço de referência, uma vez que é uma das bases que pode ser empregada pelo Gestor Público como parâmetro de pesquisa de mercado [46], sendo considerada a ideal para este estudo, uma vez que não sofre distorções por valores muito altos ou muito baixos [47].

\subsection{LIMITAÇÕES DO ESTUDO}

Este estudo apresenta as seguintes limitações: 1) a utilização somente do COMRJ como base dos resultados das aquisições de Gêneros Alimentícios da MB; 2) a análise de somente uma modalidade de compra do PAA, o PAA-CI, uma vez que é a modalidade que se aplica aos Órgãos da Administração Pública, em que se enquadra o COMRJ; 3) a seleção de somente oito itens como parâmetros de comparação, os quais servem de base para as discussões deste estudo; e 4) a possibilidade de que os preços de aquisição possam sofrer variações de acordo com a produção nos períodos de safra e entressafra, bem como podem ser afetados por fenômenos econômicos, sejam eles: a oferta e demanda; a disponibilidade de estoques, mudanças climáticas, estratégias financeiras, entre outros [48].

\section{RESULTADOS E DISCUSSÃO}

Os resultados e discussão ocorreram tangenciando três aspectos. O primeiro visa observar os preços obtidos nas aquisições de alimentos no PE-SRP, como também aqueles que utilizaram o PAA-CI em 2018, no âmbito da MB, com resultados do COMRJ. Já no segundo, o foco é expandido para todo o Governo Federal, a fim de alcançar uma quantidade maior de dados e, dessa forma, contribuir com uma análise mais robusta acerca das diferenças de preços. Por último, foi produzida uma comparação entre as aquisições de alimentos realizadas pelo COMRJ empregando o PAA-CI e as aquisições dos Órgãos do Governo 
Federal por intermédio do PE-SRP.

Nos dois tipos de processos de compra analisados, as regras de fornecimento levaram em consideração as mesmas variáveis, quais sejam: capacidade de armazenagem; movimentação dos estoques; e atendimento de pedidos por período, não havendo, portanto, grandes diferenças nos prazos de entrega. A diferença existente se caracteriza em termos de procedimentos, em que no SRP a vigência é de 12 meses e não há a obrigatoriedade de compra, enquanto na CP-AF, a aquisição é obrigatória em sua totalidade, proporcionando, com isso, uma certa segurança aos vendedores diretos e indiretos habilitados para o PAA-CI no que tange à sua capacidade de produção e também aos recebimentos de pagamentos.

Quanto ao o número de fornecedores participantes nos processos de obtenção, observa-se que a quantidade de participantes da CP-AF, via PAA-CI, ainda é menor quando comparado ao PE-SRP. Salgado et al [19] afirmam que há uma preocupação em garantir o acesso ao mercado para os produtos de AF com o PAA-CI. Para Magalhães e Soares [49], há uma expectativa de preços mais atrativos no PAA-CI, em decorrência do futuro aumento da oferta dos produtos ocasionados pelo estímulo do governo.

No que concerne à economia de escala, esta pode ser observada nos menores preços apresentados nos resultados das aquisições realizadas por PE-SRP quando comparados às CPAF, correspondendo aos apontamentos de Trautmann, Bals e Hartmann [35] e Karjalainen [36].

\subsection{PAA-CI NO COMRJ}

Em face ao atendimento da expansão das políticas públicas pelo PAA-CI, a Tabela 1 evidencia a evolução do COMRJ no período compreendido entre 2017 e 2018.

TABELA 2 - Evolução do PAA-CI no COMRJ entre 2017- 2018

\begin{tabular}{c|c|c|c}
\hline Ano & $\mathbf{2 0 1 7}$ & $\mathbf{2 0 1 8}$ & Crescimento em (\%) \\
\hline Quantidade de itens & 9 & 17 & $88,89 \%$ \\
\hline R\$ & $\mathrm{R} \$ 4.478 .816,32$ & $\mathrm{R} \$ 10.213 .981,38$ & $128,05 \%$ \\
\hline Unidades Familiares Atendidas & 223 & 527 & $136,32 \%$ \\
\hline
\end{tabular}

Fonte: Brasil [41], adaptado pelo autor.

A Tabela 2 demonstra um avanço de investimento financeiro e unidades familiares atendidas de $128 \%$ e $136,32 \%$, respectivamente, confirmando a inclusão de produtos da AF, através do PAA-CI, na cadeia de suprimentos da MB.

Foram extraídas informações referentes às aquisições de alimentos realizadas pelo COMRJ em 2018, nas modalidades PE-SRP e PAA-CI, a fim de confrontar seus resultados. A Tabela 2 demonstra os resultados da pesquisa:

TABELA 3 - Comparação entre os valores de aquisição do PE-SRP e do PAA-CI em 2018 (continha)

\begin{tabular}{c|r|r|r|r}
\hline Item & UF & \multicolumn{1}{|c|}{ Pregão COMRJ } & \multicolumn{1}{c|}{ CP-AF COMRJ } & Variação \\
\hline Arroz branco tipo 1 1 kg & $\mathrm{kg}$ & 2,89 & 2,73 & $-5,54 \%$ \\
\hline Arroz parboilizado tipo 1 & $\mathrm{kg}$ & 3,09 & 2,63 & $-14,89 \%$ \\
\hline Café torrado tipo II & $\mathrm{kg}$ & 20,63 & 21,38 & $3,64 \%$ \\
\hline Farinha de mandioca & $\mathrm{kg}$ & 3,65 & 4,36 & $19,45 \%$ \\
\hline Feijão preto tipo 1 & $\mathrm{kg}$ & 3,5 & 4,74 & $35,43 \%$ \\
\hline
\end{tabular}

TABELA 3 - Comparação entre os valores de aquisição do PE-SRP e do PAA-CI em 2018 (conclusão)

\begin{tabular}{c|r|r|r|r}
\hline Item & UF & \multicolumn{1}{|c|}{ Pregão COMRJ } & \multicolumn{1}{l|}{ CP-AF COMRJ } & Variação \\
\hline Leite em pó integral & $\mathrm{kg}$ & 13,76 & 22,00 & $59,88 \%$ \\
\hline Lombo suíno & $\mathrm{kg}$ & 8,9 & 14,75 & $65,73 \%$ \\
\hline Pernil suíno sem osso & $\mathrm{kg}$ & 6,86 & 11,70 & $70,55 \%$ \\
\hline
\end{tabular}

Fonte: Painel de Preços e Brasil [41] adaptado pelo autor. 
A Tabela 3 nos revela que $75 \%$ dos itens analisados apresentaram preços superiores nas aquisições do COMRJ na modalidade PAA-CI, dos quais os itens: Lombo Suíno e Pernil Suíno sem osso apresentaram um valor de aquisição superior ao processo de aquisição realizado pela modalidade PE-SRP em 65,73\% e 70,55\%, respectivamente. Em contrapartida, os itens: Arroz branco tipo 1 e Arroz parboilizado se mostraram mais econômicos quando adquiridos na modalidade PAA-CI. A Figura 1 demonstra bem essa comparação:

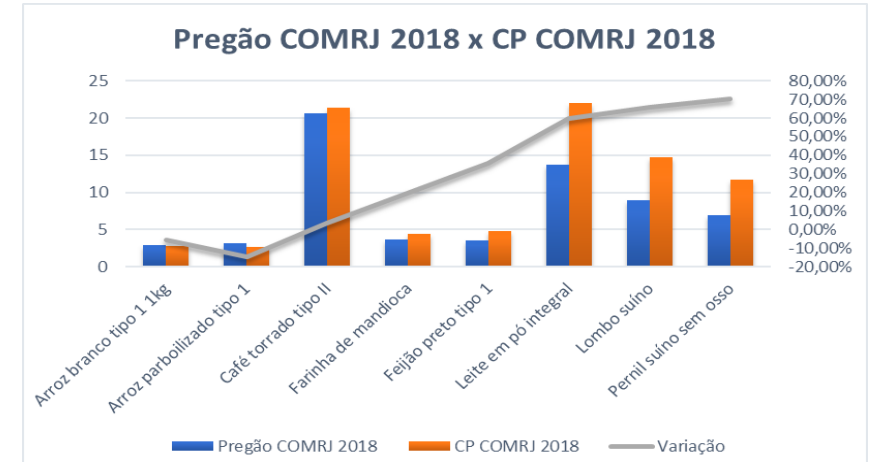

FIGURA 1 - Comparação entre os valores unitários de aquisição do PE-SRP e do PAA-CI (COMRJ 2018)

Fonte: Painel de Preços e Brasil [41] adaptado pelo autor.

\subsection{OBSERVAÇÕES DAS AQUISIÇÕES DE ALIMENTOS NO GOVERNO FEDERAL}

Tendo em vista os poucos processos de CP-AF conduzidos no COMRJ, desde que o Decreto 8.473/15 entrou em vigência, adicionou-se a análise comparativa das aquisições de gêneros alimentícios dos órgãos da Administração Pública Federal no ano de 2018, realizadas por PE-SRP e pelo PAA-CI.

TABELA 4 - Aquisição de alimentos pelos Órgãos da Administração Pública em 2018

\begin{tabular}{c|c|c|c|c|c|c}
\hline \multirow{2}{*}{ Item } & \multirow{2}{*}{ UF } & \multicolumn{2}{|c|}{ Pregão Eletrônico } & \multicolumn{2}{c|}{ Chamadas Públicas } & \multirow{2}{*}{ Variação } \\
\cline { 3 - 6 } & & Quantidade & Mediana & Quantidade & Mediana & \\
\hline Arroz branco tipo 1 & $\mathrm{kg}$ & 100 & 2,41 & 13 & 2,73 & $13,28 \%$ \\
\hline Arroz parboilizado tipo 1 & $\mathrm{kg}$ & 71 & 2,36 & 4 & 2,35 & $-0,42 \%$ \\
\hline Café torrado tipo II & $\mathrm{kg}$ & 62 & 16,74 & 6 & 20,19 & $20,61 \%$ \\
\hline Farinha de mandioca & $\mathrm{kg}$ & 238 & 3,81 & 12 & 5,20 & $36,35 \%$ \\
\hline Feijão preto tipo 1 & $\mathrm{kg}$ & 93 & 4,05 & 16 & 4,75 & $17,16 \%$ \\
\hline Leite em pó integral & $\mathrm{Kg}$ & 72 & 18,00 & 7 & 19,67 & $9,28 \%$ \\
\hline Lombo suíno & $\mathrm{Kg}$ & 69 & 12,55 & 4 & 16,08 & $28,09 \%$ \\
\hline Pernil suíno sem osso & $\mathrm{Kg}$ & 94 & 10,25 & 5 & 11,70 & $14,15 \%$ \\
\hline
\end{tabular}

Fonte: Painel de Preços e Brasil [41], adaptado pelo autor.

Na Tabela 4, a demonstração do percentual de variação entre os preços praticados tem o intuito de comparar a vantagem econômica nos dois modelos de aquisição, considerando a Administração Pública como um todo. 


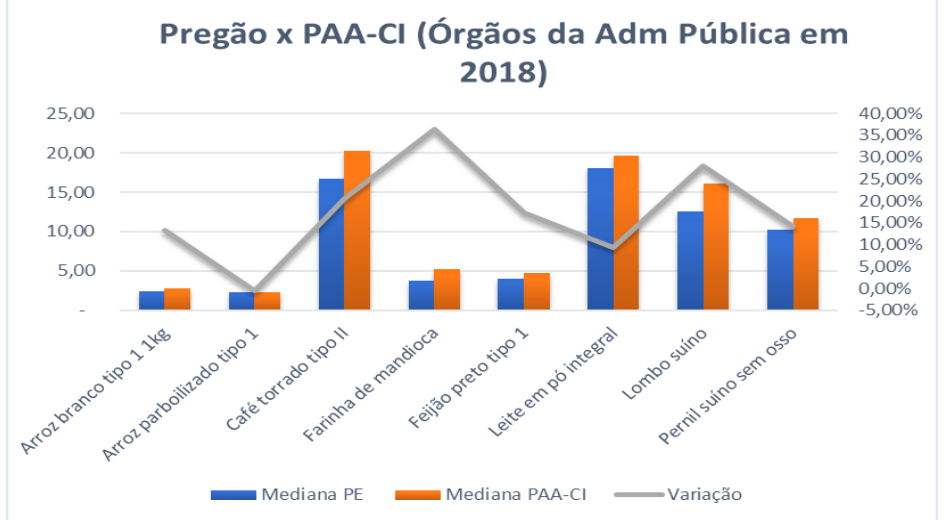

FIGURA 2 - Aquisição de alimentos pelos Órgãos da Administração Pública em 2018 Fonte: Painel de Preços e Brasil [41], adaptado pelo autor.

Das análises efetuadas da Tabela 4 e Figura 2, pode-se afirmar que as aquisições decorrentes de PAA-CI, em aproximadamente $88 \%$ dos casos estudados, apresentam custo de aquisição superiores aos do PE-SRP, entretanto, nos $12 \%$ restantes, configurado especificamente com o item Arroz parboilizado, a aquisição refletiu um custo inferior, sendo, portanto, mais vantajoso economicamente. Contudo, em termos percentuais, a citada variação de preços foi pouco expressiva, na ordem de - 0,42\%.

\subsection{PAA-CI NO COMRJ X PE-SRP DO GOVERNO FEDERAL}

Com o propósito de ampliar a validade dos achados, optou-se por realizar uma análise comparativa, particular dos preços praticados no PAA-CI do COMRJ, com os demais conduzidos por PE-SRP pelos Órgãos da Administração Pública Federal.

TABELA 5 - Análise comparativa PAA-CI do COMRJ e PE-SRP do Governo Federal, 2018.

\begin{tabular}{c|c|c|c|c}
\hline Item & UF & Mediana SRP Governo Federal & PAA-CI COMRJ & Variação \\
\hline Arroz branco tipo 1 1 kg & $\mathrm{kg}$ & 2,41 & 2,73 & $13,28 \%$ \\
\hline Arroz parboilizado tipo 1 & $\mathrm{kg}$ & 2,36 & 2,63 & $11,44 \%$ \\
\hline Café torrado tipo II & $\mathrm{kg}$ & 16,74 & 21,38 & $27,72 \%$ \\
\hline Farinha de mandioca & $\mathrm{kg}$ & 3,81 & 4,36 & $14,44 \%$ \\
\hline Feijão preto tipo 1 & $\mathrm{kg}$ & 4,05 & 4,74 & $17,04 \%$ \\
\hline Leite em pó integral & $\mathrm{kg}$ & 18,00 & 22,00 & $22,22 \%$ \\
\hline Lombo suíno & $\mathrm{kg}$ & 12,55 & 14,75 & $17,53 \%$ \\
\hline Pernil suíno sem osso & $\mathrm{kg}$ & 10,25 & 11,70 & $14,15 \%$ \\
\hline
\end{tabular}

Fonte: Painel de Preços e Brasil [41], adaptado pelo autor.

Nota-se com as evidências da Tabela 5 que, em 100\% dos casos, os resultados dos preços dos itens selecionados do PAA-CI do COMRJ foram superiores aos dos PE-SRP no âmbito da Administração Pública Federal. Dessa forma, pode-se afirmar que as aquisições de alimentos selecionadas, demonstram ser mais onerosas quando utilizado o PAA-CI.

\section{IMPLICAÇÕES E CONSIDERAÇÕES FINAIS}

Observou-se neste trabalho a inclusão progressiva de produtos provenientes da AF, por intermédio do PAA-CI, na cadeia de suprimentos dos órgãos públicos e, principalmente no COMRJ, que é a organização alvo de estudo. Apesar do PAA ser orientado para a promoção do desenvolvimento econômico e social, na prática, o programa carece de efetividade, em termos de vantagem econômica afeta ao custo de aquisição, pois para a maioria dos itens selecionados nessa pesquisa, as contratações nesse formato têm se demonstrado mais onerosas. 
No contexto do Governo Federal, destacam-se com as maiores variações a Farinha de mandioca em 36,35\% e o Lombo suíno em 28,09\%. Todavia, para o item Arroz parboilizado, o PAA-CI alcançou preços inferiores ao PE- SRP tanto na análise estrita do COMRJ com 14,89\%, quanto na análise ampla do Governo Federal, com -0,42\%.

Dessa forma, percebe-se que para o gestor público, atualmente é um grande trade off cumprir às exigências do PAA-CI e, concomitantemente, produzir aquisições econômicas mediante orçamentos financeiros escassos.

Por outro lado, têm-se que o programa em comento ainda é incipiente, dado que sua obrigatoriedade só ocorreu concretamente a partir de 2016 e que a inserção de acesso do agricultor pelo PAA-CI nas compras governamentais tende a produzir uma aceleração do crescimento da oferta e, por consequência, queda dos preços, ensejando talvez uma equiparação de preços no futuro, situação que não pode ser verificada neste estudo.

Ademais, sugere-se, para trabalhos futuros, a ampliação deste tipo de pesquisa para outros tipos de alimentos, pois, à medida que outros itens forem selecionados, achados mais consistentes serão descobertos.

\section{REFERÊNCIAS BIBLIOGRÁFICAS}

[1] SILVA, R L. Compras Centralizadas e Descentralizadas: estudo de caso sobre os impactos de um modelo híbrido de compras na obtenção de gêneros alimentícios pela Marinha do Brasil. Dissertação (mestrado). Pontifícia Universidade Católica do Rio de Janeiro. 2016.

[2] BRASIL. Lei $\mathbf{n}^{\mathbf{0}}$ 8.666, de 21 de junho de 1993. Institui normas para licitações e contratos da Administração Pública e dá outras providências. Diário Oficial da República Federativa do Brasil, Brasília, 22 jul. 1993. Disponível em: <http://www.planalto.gov.br/ccivil_03/leis/L8666cons.htm>. Acesso em 20 fev. 2019.

Decreto $n^{0}$ 7.892, de 23 de janeiro de 2013. Regulamenta o Sistema de Registro de Preços previsto no art. 15 da Lei 8.666, de 21 de junho de 1993. Diário Oficial da República Federativa do Brasil, Brasília, DF, 23 jan. 2013. Disponível em: <http://www.planalto.gov.br/ccivil_03/_Ato2011-2014/2013/Decreto/D7892.htm>. Acesso em: 28 fev. 2019.

[4] . Marinha do Brasil. Secretaria-Geral da Marinha. Normas sobre Licitações, Acordos e Atos Administrativos - SGM-102. 4. rev. Brasília, DF, 2013.

[5] . Decreto $\mathbf{n}^{\mathbf{0}}$ 8.473, de 22 de junho de 2015. Estabelece, no âmbito da Administração Pública federal, o percentual mínimo destinado à aquisição de gêneros alimentícios de agricultores familiares e suas organizações, empreendedores familiares rurais e demais beneficiários da Lei $\mathrm{n}^{\circ}$ 11.326, de 24 de julho de 2006, e dá outras providências. Diário Oficial da República Federativa do Brasil, Brasília, DF, 23 jun. 2015. Disponível em:

<http://www.planalto.gov.br/ccivil_03/_Ato2015-2018/2015/Decreto/D8473.htm>. Acesso em: 28 fev. 2019. alongamento de dívidas oriundas de operações de crédito rural, e dá outras providências. Diário Oficial da República Federativa do Brasil, Brasília, 3 jul. 2003. Disponível em: <http://www.planalto.gov.br/ccivil_03/LEIS/2003/L10.696.htm>. Acesso em 04 mar. 2019. 

RIO DE JANEIRO, RJ, BRASIL - 06 A 08 DE NOVEMBRO DE 2019 do Programa de Aquisição de Alimentos da Agricultura Familiar: orientações e marco legal. 2018. Disponível em:

$<$ http://www.mds.gov.br/webarquivos/publicacao/seguranca_alimentar/

SESAN_Orientac\%CC\%A7o\%CC\%83es_Marco_Legal_PAA.pdf >. Acesso em: 22, mar. 2019.

[8] . Ministério do Desenvolvimento Social. Programa de Aquisição de Alimentos Modalidade Compra Institucional. Relatório de Execução 2017. Brasília: Ministério do Desenvolvimento Social, 44 p., 2018. Disponível em:

$<$ http://www.mds.gov.br/webarquivos/arquivo/seguranca_alimentar/compra_institucion al/BALANCO_RELATORIO_EXECUCAO_PAACI_2017.pdf>. Acesso em: 22, mar. 2019.

[9] . Secretaria Especial de Agricultura Familiar e do Desenvolvimento Agrário. Plano Safra 2017-2018. 2016. Disponível em:

<http://www.mda.gov.br/sitemda/sites/sitemda/files/user_img_1684/3Baixa_Cartilha_Pl ano_Safra_2017.pdf>. Acesso em: 22, mar. 2019.

[10] . Ministério de Desenvolvimento Social. Catálogo de Produtos Ofertados pela Agricultura Familiar. 2018. Disponível em:

<http://www.mds.gov.br/webarquivos/arquivo/seguranca_alimentar/Simposio_PAA/ SIMPOSIO_NACIONAL/Catalogo_Produtos_Agricultura_Familiar.pdf $>$. Acesso em: 22, mar. 2019.

[11] SCHNEIDER, S. Teoria social, agricultura familiar e pluriatividade. Revista Brasileira de Ciências Sociais, São Paulo, v. 18, n. 51, p. 99-123, fev/2003.

[12] FAGUNDES, J.; DANTAS, A. T. Poder de Compra do Estado e Competitividade: implicações para as políticas públicas. Nova Economia, v. 7, n. 2. dez. 1997.

[13] ARNALD, R.; WHITFORD, A. B. Making Environmental Self-Regulation Mandatory. Global Environmental Politics, Volume 6, Number 4, November 2006, pp. 1-12 Article.

[14] MORAES, C. Desenvolvimento nacional, licitações e fiscalização pelos tribunais de contas. Revista do TCU, n.136. p.66-75. 2016.

[15] BRASIL. Tribunal de Contas da União. Revista do TCU, n.134. 2015. Disponível em: $<$ https://www.google.com/url? $\mathrm{sa}=\mathrm{t} \& \mathrm{rct}=\mathrm{j} \& \mathrm{q}=$ \&esrc $=\mathrm{s} \&$ source $=$ web\&cd=2\&ved=2ahUKEwi4tKaZm9TgAhUnEbkG HZdHBYkQFjABegQIAhAC\&url=https\%3A\%2F\%2Fportal.tcu.gov.br\%2Flumis \%2Fportal\%2Ffile\%2FfileDownload.jsp\%3FfileId \%3D8A8182A154E4F52C0154F346BB5A6FF1\&usg=AOvVaw0x49p3r8ScwiFzgVCb JEll>. Acesso em: 24, fev. 2019. Ministério de Desenvolvimento Social. Programa de Aquisição de Alimentos: modalidade Compra Institucional (PAA-CI). 2017. Disponível em: $<$ https://www.mds.gov.br/webarquivos/publicacao/seguranca_alimentar/ Compra_Institucional_PAA_3.pdf>. Acesso em: 22, mar. 2019. Lei $n^{0}$ 12.512, de 14 de outubro de 2011. Institui o Programa de Apoio à Conservação Ambiental e o Programa de Fomento às Atividades Produtivas Rurais; altera as Leis $n^{0}$ s 10.696, de 2 de julho de 2003, 10.836, de 9 de janeiro de 2004, e 11.326, de 24 de julho de 2006. Diário Oficial da União. Brasília, 17 jul. 2011. 
Disponível em:

<http://www.planalto.gov.br/ccivil_03/_ato2011-2014/2011/Lei/L12512.htm>. Acesso em: 20, mar. 2019.

[18] GHIZELINI, A. A. M. Atores Sociais, Agricultura Familiar Camponesa e o Espaço Local: Uma Análise a partir do Programa de Aquisição de Alimentos. 2010. 267 f. Tese de Doutorado em Sociologia-Faculdade de Ciências Humanas, Letras e Artes. Universidade Federal do Paraná, Curitiba, 2010.

[19] SALGADO, R J S F; TEIXEIRA, E C; CUNHA, W A. Contribuição dos Programas de Compra Institucional (PAA e PNAE) para a estabilização dos preços agrícolas em Minas Gerais. Revista de Estudos Sociais, n. 37, v. 18, p. 22, 2016.

[20] BRASIL. Decreto $\mathbf{n}^{0}$ 7.775, de 4 de julho de 2012. Regulamenta o art. 19 da Lei ${ }^{\circ}$ 10.696, de 2 de julho de 2003, que institui o Programa de Aquisição de Alimentos, e o Capítulo III da Lei ${ }^{\circ}$ 12.512, de 14 de outubro de 2011, e dá outras providências. Diário Oficial da União. Brasília, 05 jul. 2012. Disponível em: <http://www.planalto.gov.br/ccivil_03/_Ato2011-2014/2012/Decreto/D7775.htm>. Acesso em: 20, mar. 2019.

[21] _. Resolução no 50, de 26 de setembro de 2012. Secretaria Nacional de Segurança Alimentar e Nutricional. Grupo Gestor do Programa de Aquisição de Alimentos. Dispõe sobre a sistemática de funcionamento da modalidade de execução Compra Institucional, no âmbito do Programa de Aquisição de Alimentos da Agricultura Familiar.

$<$ http://www.mds.gov.br/webarquivos/arquivo/seguranca_alimentar/compra_institucion al/RESOLUCAO_N50_26SETEMBRO2012.pdf>. Acesso em: 20, mar. 2019.

[22] _ Ministério do Planejamento, Desenvolvimento e Gestão. Instrução Normativa no 02 , de 29 de março de 2018. Dispõe sobre a Compra Institucional de alimentos fornecidos por agricultores familiares e pelos demais beneficiários da Lei ${ }^{0} 11.326$, de 24 de julho de 2006. Diário Oficial da União. 02, abr. 2018.

<www.mds.gov.br/webarquivos/arquivo/seguranca_alimentar/compra_institucional/ Instrução Normativa ${ }^{\circ}$ 2, de 29 de março de 2018 - Diário Oficial da União - Imprensa Nacional.pdf>. Acesso em: 20, mar. 2019.

[23] PAULA, N. F. Colhendo os frutos: dificuldades e conquistas da modalidade do PAA compra-institucional em uma universidade pública. Dissertação (mestrado). Universidade Federal do Paraná. Curitiba: 2016, pp. 97.

[24] MATTEI, L. Políticas públicas de combate à fome: o caso do Programa de Aquisição de Alimentos da Agricultura Familiar no Estado de Santa Catarina. Cadernos do CEAM (UnB), v. 7, p. 75-105, 2007.

[25] BRASIL. Lei $\mathbf{n}^{0}$ 11.326, de 24 de julho de 2006. Estabelece as diretrizes para a formulação da Política Nacional da Agricultura Familiar e Empreendimentos Familiares Rurais. Diário Oficial da República Federativa do Brasil, Brasília, 25 jul. 2006. Disponível em: <http://www.planalto.gov.br/ccivil_03/_Ato2004-2006/2006/Lei/L11326.htm>. Acesso em 04 mar. 2019. . Constituição (1988). Constituição da República Federativa do Brasil. Brasília, DF - 1988. Disponível em: $<$ http://www.planalto.gov.br/ccivil_03/constituicao/constituicaocompilado.htm>. Acesso em: 01 mar. 2019. 
[27] GIGANTE, T. C. Compras Governamentais: Estudo de caso sobre contratações centralizadas de serviços comuns pela Marinha do Brasil. Dissertação (mestrado) Pontifícia Universidade Católica do Rio de Janeiro, Departamento de Engenharia Industrial, 160 f., 2014.

[28] BRASIL. Lei no 10.520, de 17 de junho de 2002. Institui, no âmbito da União, Estados, Distrito Federal e Municípios, nos termos do art. 37, inciso XXI, da Constituição Federal, modalidade de licitação denominada pregão, para aquisição de bens e serviços comuns, e dá outras providências. Diário Oficial da República Federativa do Brasil, Brasília, 18 jul. 2002. Disponível em: <http://www.planalto.gov.br/ccivil_03/leis/2002/L10520.htm>. Acesso em 04 mar. 2019.

[29] JUSTEN FILHO, M. Comentários à lei de licitações e contratos administrativos. 17. ed. São Paulo: Revista dos Tribunais, 2016.

[30] BRASIL. Tribunal de Contas da União. Acórdão no 1.285/2015. Plenário. Relator: Ministro Benjamin Zymler. Sessão de 27/5/2015. Disponível em: $<$ https://pesquisa.apps.tcu.gov.br/\#/documento/acordao-completo/*/NUMACORDAO \%253A1285\%2520ANOACORDAO\%253A2015\%2520COLEGIADO\%253A \%2522Plen\%25C3\%25A1rio\%2522/DTRELEVANCIA\%20desc, \%20NUMACORDAOINT\%20desc/0/\%20?uuid=a082ccb0-56a5-11e9-b5b1bf255de06441>. Acesso em: 10 mar. 2019.

[31] FILHO, J S C. Manual de Direito Administrativo, 23 ${ }^{\text {a }}$ ed. Rio de Janeiro: Lumen Juris, 2010.

[32] BITTENCOURT, S. Licitação de Registro de Preços: comentários ao Decreto $\mathbf{n}^{\mathbf{o}}$ 7.892, de 23 de janeiro de 2013, alterado pelo Decreto $n^{\circ} 8.250$, de 23 de maio de 2014. 4. ed. rev. atual. e ampl. Belo Horizonte: Fórum, 2015.

[33] AMORIN, V. A. J. Licitações e Contratos Administrativos: teoria e jurisprudência. Brasília: Senado Federal, 2017.

[34] BAILY, P. et al. Compras: princípios e administração. São Paulo: Atlas, 2011.

[35] TRAUTMANN, G.; BALS, L.; HARTMANN, E. Global sourcing in integrated network structures: the case of hybrid purchasing organizations. Journal of International Management, v. 15, n. 2, p. 194-208, 2009.

[36] KARJALAINEN, K. Estimating the cost effects of purchasing centralizationEmpirical evidence from framework agreements in the public sector. Journal of purchasing and supply management, 17(2), 87-97. 2011.

[37] BRASIL. Licitações e contratos: orientações e jurisprudência do TCU. 4. ed. rev., atual. e ampl. - Brasília: TCU, 2010. Disponível em: $<$ http://portal2.tcu.gov.br/portal/pls/portal/docs/2057620.PDF>. Acesso em 24/3/2019.

[38] MESSIAS, L. S; CAMARGO, R. A. L. A chamada pública como alternativa à licitação: seu uso na aquisição de produtos da agricultura familiar para a alimentação escolar. Dissertação (mestrado profissional - políticas públicas). Universidade Estadual Paulista “Júlio de Mesquita Filho”, Faculdade de Ciências Humanas e Sociais. Franca: 2018, pp. 87.

[39] TRICHES, R. M.; BACCARIN, J. G. . Interações entre alimentação escolar e agricultura familiar para o desenvolvimento local. In: Carla Rosane Paz Arruda Teo; 
Rozane Marcia Triches. (Org.). Alimentação escolar: construindo interfaces entre saúde, educação e desenvolvimento. 1 ed. Chapecó (SC): Argos, 2016, v. 1, p. 89-110.

[40] OLDEKOP, J. A.; CHAPPELL, M. J.; PEIXOTO, F. E. B.; PAGLIA, A. P.; RODRIGUES, M. S. P.; EVANS, K. L. Linking Brazil's food security policies to agricultural change. Agriculture Human Value 7:779-793. 2015.

[41] BRASIL. Ministério da Cidadania - Secretaria Especial do Desenvolvimento Social. Compras da Agricultura Familiar - Resultados das Chamadas Públicas. 2019. Disponível em: <http://mds.gov.br/compra-da-agricultura-familiar/resultados-dechamadas-publicas>. Acesso em: 22, mar. 2019.

[42] DE JESUS, A. P.; NOGUEIRA, A. S.; ALMEIDA, R. H. C.; DOS SANTOS, M. A. S. O Programa de Aquisição de Alimentos (PAA): estudo de caso sobre limitações e avanços na modalidade Compra Institucional em Belém, Estado do Pará.

Enciclopédia Biosfera, Centro Científico Conhecer, v. 51, n. 28; p. 732. Goiânia - 2018.

[43] MILANI, A. A; GASPAR, V; ALBRECHT, A. J. P; FAUSTO, D. A; MIGLIAVACCA, R. A. Processo de gestão da carteira de clientes. Revista iPecege 1(2): 169-186, 2015.

[44] BRASIL. Resolução n $\mathbf{n}^{\mathbf{7}} \mathbf{7 8}$, de 8 de setembro de 2017. Secretaria Nacional de Segurança Alimentar e Nutricional. Grupo Gestor do Programa de Aquisição de Alimentos Estabelece as condições para a aquisição de produtos processados, beneficiados ou industrializados no âmbito do Programa de Aquisição de Alimentos. 2017.

[45] MARTINELLI, S. S.; SOARES, P.; FABRI, R. K.; CAMPANELLA, G, R, A.; ROVER, O, J.; CAVALLI, S. B. Potencialidades da compra institucional na promoção de sistemas agroalimentares locais e sustentáveis: o caso de um restaurante universitário. Segurança Alimentar e Nutricional, Campinas, v.22, n.1, p.558-573, 2015.

[46] BRASIL. Secretaria de Logística e Tecnologia da Informação do Ministério do Planejamento, Orçamento e Gestão. Instrução Normativa no ${ }^{5}$, de 27 de junho de 2014. Dispõe sobre o procedimento administrativo de pesquisa de preços para a aquisição de bens e contratação de serviços em geral. Disponível em: $<$ https://www.comprasgovernamentais.gov.br/index.php/legislacao/instrucoesnormativas/301-instrucao-normativa-n-5-de-27-de-junho-de-2014-compilada>. Acesso em: 28 fev. 2019.

[47] . Ministério do Desenvolvimento, Orçamento e Gestão. Secretaria de Gestão. Caderno de Logística: pesquisa de preço. 2017.

$<$ https://www.comprasgovernamentais.gov.br/images/conteudo/ArquivosCGNOR/ 2.Caderno-de-Logistica_Pesquisa-de-Precos-2017.pdf>. Acesso em: 22, mar. 2019.

[48] LIMA, F. V. A variação dos preços do milho e sua relação com fatores climáticos. Trabalho de Conclusão de Curso. Universidade Estadual de Campinas - Faculdade de Engenharia Agrícola. 2016. 55 p.

[49] MAGAlHAES, A. M.; SOARES, A. Os impactos do PAA-Leite sobre o Preço, a Produção e a renda da Pecuária Leiteira. Cadernos de Estudos Desenvolvimento Social em Debate, Brasília, n. 3, p. 2006. 